\title{
Color stability of bulk-fill composites exposed to different beverages and the effect of whitening dentifrices
}

\author{
Musab Kamheya ${ }^{1 *}$, Burak Gumustas ${ }^{2}$ and Begum Guray Efes ${ }^{3}$ \\ ${ }^{1}$ Department of Restorative Dentistry, Istanbul University, Capa, Istanbul, Turkey \\ ${ }^{2}$ Department of Restorative Dentistry, Istanbul Medipol University, Istanbul, Turkey \\ ${ }^{3}$ Department of Restorative Dentistry, Istanbul University, Capa, Istanbul, Turkey
}

\begin{abstract}
Objectives: Discoloration of resin-based composites by colored solutions is a common problem in dentistry and use of whitening dentifrices is becoming increasingly popular. However, it is not clear if whitening dentifrices can remove stains from bulk-fill composite resins.

Material and Methods: we evaluated the discoloration of two bulk-fill composite resins (3M Filtek Bulk Fill, Tetric EvoCeram Bulk Fill) aged using 10,000 thermocycles $\left(5^{\circ} \mathrm{C}-55^{\circ} \mathrm{C}\right)$ and on exposure to several common beverages, including cola, coffee, red wine, and water, and the amount of reduction of discoloration after brushing with whitening dentifrices. The colors of all specimens before and after storage in the solutions and after brushing were measured by colorimetry based on the CIE Lab system and the differences in color calculated. The data were analyzed by two-way analysis of variance and Tukey's honest significant difference test.

Results: The restorative material, staining agent, and the interaction between these two factors were found to play a significant role in color changes. Water consistently showed the lowest $\Delta \mathrm{E}^{*}$ value of all the staining agents, red wine showed the highest $\Delta \mathrm{E}$ value with Tetric EvoCeram Bulk Fill, and coffee showed the highest $\Delta \mathrm{E}$ value with Filtek Bulk Fill. After staining, brushing with whitening dentifrices (Crest 3D White, Crest 3D White Accelerator) was associated with decreased $\Delta \mathrm{E}$ values compared with those obtained after staining, but with no significant difference between the dentifrice groups ( $\mathrm{p}>0.05$ ).
\end{abstract}

Conclusions: Although whitening dentifrices cannot remove all discoloration of composites caused by common beverages, they can be used to reduce it.

\section{Introduction}

Resin-based composites have been successfully used in dentistry as posterior restorations for many years [1]. However, several factors limit the performance of these composites, in particular, the depth of cure and degree of conversion [2]. Recently, a new class of resin-based composites, the so-called "bulk-fill" composites, has been introduced in the dental market to save time and cost [3]. The unique advantage of these new materials is that they can be placed in 4-mm thickness bulks and be cured in one step instead of the current incremental placement technique, without adverse effects on polymerization shrinkage, cavity adaptation, or degree of conversion.

Any esthetic restorative material should duplicate the color of a natural tooth, and the success of an esthetic restoration depends first on the color match and then on the color stability of the material [4]. However, a major disadvantage is the discoloration of these materials after prolonged exposure to the oral environment. Extrinsic staining may be a result of insufficient polymerization, heat, water sorption, or adsorption of dye substances from dietary sources, and inadequate oral hygiene $[5,6]$. An unacceptable color match is the primary reason for replacement of composite resin restorations [7-9].

Previous studies addressing color stability have shown that beverages such as coffee, tea, red wine, and cola, along with mouth rinses, produce varying degrees of staining in auto-cured and lightcured composite resin restorative materials. The staining potential of these beverages and solutions varies according to their composition and properties [10-12].

Once staining has occurred, brushing with dentifrices, repolishing, and bleaching procedures can remove the stains partially or even completely. The modern whitening dentifrices are attractive as advertised and may contain additional chemical agents that augment their abrasive cleaning activity by aiding removal and/or prevention of extrinsic stains. The ingredients studied in the past have included surfactants, peroxide, enzymes, citrate, pyrophosphates, and hexametaphosphate [13-15].

The aim of the present study was to evaluate whether the discoloration of bulk-fill resin composites can be controlled by mild surface abrasion (tooth brushing) after exposure to a neutral medium or an alcoholic or acidic medium rich in staining agents (e.g., red wine). The null hypotheses tested were: (1) bulk-fill resin composites stain to a similar extent when aged in a discolorant medium; (2) aging in different types of medium (neutral, acidic, or alcoholic) does not increase the staining of resin composites; and (3) the type of dentifrice used influences the extent of removal of staining from the composite resin.

\section{Methodology}

\section{Study Design}

This in vitro study had a factorial design that included the following: two bulk-fill resin composites, i.e., Tetric EvoCeram Bulk Fill (universal

Correspondence to: Musab Kamheya, Department of Restorative Dentistry, Istanbul University, Capa, Istanbul, Turkey, Tel: +90 53807340 43; E-mail: d_maq2111@yahoo.com

Key words: Composite, Color, Dentifrices, Spectrophotometry

Received: March 12, 2018; Accepted: March 27, 2018; Published: March 30 2018 
shade A; Ivoclar-Vivadent, Schaan, Liechtenstein, Germany) and Filtek Bulk Fill (shade A2; 3M ESPE, St. Paul, MN, USA), aging conditions (firstly thermocycle aging and then when exposed to deionized water, coffee, cola, or red wine), treatment (brushing with regular or accelerated whitening dentifrice), and assessments over time (Figure 1). The characteristics of the resin composites investigated are shown in Table 1. Measurements for each specimen were compared at different time points (repeated-measures approach). The variable investigated was color change $(\Delta \mathrm{E})$.

\section{Preparation of specimens}

Eighty disc-shaped specimens, $10 \mathrm{~mm}$ in diameter and 2-mm thick, were prepared for each composite resin (giving a total of 160 specimens) using a customized cylindrical metal mold. After pouring the composite material into the mold, a polyester strip (Mylar; SS White Company, Philadelphia, PA, USA) was pressed onto the mold surface with a glass plate to obtain a flat surface without formation of bubbles. The composite material was polymerized from both the top and bottom sides for $20 \mathrm{~s}$ according to the manufacturer's recommendations using a halogen light-curing unit (Optilux 501; Kerr Manufacturing Inc., Orange, CA, USA) operating in standard mode and emitting not less than $850 \mathrm{~mW} / \mathrm{cm}^{2}$, as measured using a radiometer that was placed on the curing unit before starting polymerization. The guide of the lightcuring unit was placed perpendicular to the specimen surface, and the distance between the light source and specimen was standardized using a 1-mm glass slide. The top surfaces of all specimens were then sequentially polished with medium, fine, and super-fine aluminum oxide-impregnated discs (Sof-Lex, 3M ESPE) using a slow-speed handpiece under dry conditions for $30 \mathrm{~s}$. After each polishing step, the specimens were thoroughly rinsed with water for $10 \mathrm{~s}$ to remove debris, air-dried for $5 \mathrm{~s}$, and then polished with another disc of lower grit for the same period of time as a final polishing. The first color measurements were made after all specimens had been stored in distilled water for 24 $\mathrm{h}$ at $37^{\circ} \mathrm{C}$ to ensure complete polymerization.

\section{Assessment of color change}

Color measurements were recorded for all specimens according to the Commission International de l'Eclairage (CIE) $\mathrm{L}^{*} \mathrm{a}^{*} \mathrm{~b}^{*}$ color scale relative to the CIE standard illuminant D65 over a black background, using a reflection spectrophotometer (Minolta CM-3600D; Konica
Minolta, Tokyo, Japan). The CIE $\mathrm{L}^{*} \mathrm{a}^{*} \mathrm{~b}^{*}$ color system is a threedimensional color measurement method in which $\mathrm{L}^{*}$ refers to the lightness coordinate, which ranges in value from 0 (black)-100 (white), and $\mathrm{a}^{*}$ and $\mathrm{b}^{*}$ are chromaticity coordinates on the green-red $\left(-\mathrm{a}^{*}=\right.$ green; $+\mathrm{a}^{*}=$ red $)$ and blue-yellow $\left(-\mathrm{b}^{*}=\right.$ blue; $+\mathrm{b}^{*}=$ yellow $)$ axes, respectively. All specimens were rinsed with distilled water and blotted dry with absorbent paper before measurements were taken. Four measurements were obtained from each specimen by a single operator and were recorded at baseline (T0), after thermal aging (T1), after staining (T2), and after brushing with dentifrice (T3). Before each color measurement, the spectrophotometer was calibrated according to the manufacturer's instructions. The overall color change values $(\Delta \mathrm{E})$ were calculated as follows:

\section{CIE L*a*b*}

$$
\mathrm{E}=\left[\left(\Delta \mathrm{L}^{*}\right)^{2}+\left(\Delta \mathrm{a}^{*}\right)^{2}+\left(\Delta \mathrm{b}^{\star}\right)^{2}\right]^{1 / 2}
$$

where $\Delta \mathrm{L}^{*}$ is lightness and $\Delta \mathrm{a}^{*}$ and $\Delta \mathrm{b}^{*}$ are the differences in the green-red and blue-yellow axes, respectively.

\section{Aging conditions}

The specimens were stored in distilled water at $37^{\circ} \mathrm{C}$ for 30 days and then subjected to thermal cycling $\left(10,000 \times, 5^{\circ} \mathrm{C}-55^{\circ} \mathrm{C}\right.$, with a dwelling time of $30 \mathrm{~s}$ and a transfer time from one bath to the other of $10 \mathrm{~s}$ ) using a thermal cycling machine (Nova Ética, São Paulo, Brazil). After thermal aging, a second color measurement was made (T1).

To evaluate the color stability in the different solutions, 80 specimens from each composite resin group were subdivided into four subgroups each containing 20 specimens, which were immersed in four different solutions (distilled water, coffee, red wine, and cola). Distilled water served as the control solution. The specimens of each composite resin were individually immersed in vials containing $5 \mathrm{~mL}$ of coffee (Nescafe Classic, Nestle SA, Vevey, Switzerland), red wine (Yakut, alcohol content $14.5 \%$, Kavaklidere Co, Ankara, Turkey), or cola (The Coca-Cola Co, Istanbul, Turkey) for $24 \mathrm{~h}$ at room temperature $\left(22^{\circ} \mathrm{C}\right)$. Fifteen grams of coffee were poured into $500 \mathrm{~mL}$ of hot water and filtered after $10 \mathrm{~min}$ before being poured into the containers. The specimens were immersed in $20 \mathrm{ml}$ of staining solution in groups of five in covered glass containers and kept in the dark at room temperature for $24 \mathrm{~h}$. The solutions were not agitated. After immersion in solution, each sample was washed with distilled water for $30 \mathrm{~s}$ and

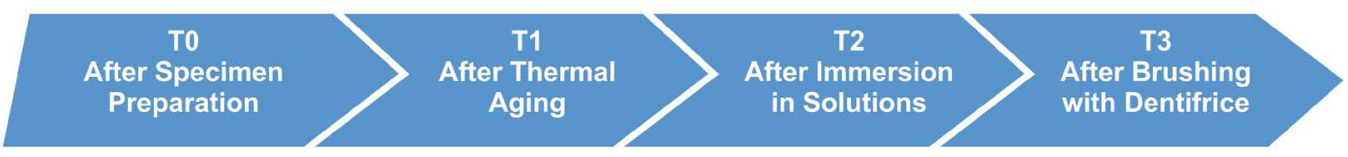

Figure 1. Measurements obtained from each specimen by a single operator

Table 1. Bulk-fill resin composites used in this study

\begin{tabular}{|c|c|c|c|c|c|}
\hline Abbr. & Resin composite and shade & Filler & Filler type & Filler size & Monomer composition \\
\hline & & Wt-Vol (\%) & & & \\
\hline \multirow[t]{4}{*}{ FBF } & Filtek Bulk & $76,5-58,4$ & - Non-agglomerated zirconia filler & $4-11 \mathrm{~nm}$ & AUDMA \\
\hline & Fill Restorative & & Aggregated zirconia/silica cluster filler & $20 \mathrm{~nm}$ & UDMA \\
\hline & $\mathrm{A} 2$ & & . Ytterbium trifluoride filler & $100 \mathrm{~nm}$ & DDDMA \\
\hline & 3M-Espe, St. Paul, MN, USA & & & & \\
\hline \multirow[t]{3}{*}{ TEC } & Tetric EvoCeram Bulk Fill & $81-61$ & - Barium glass & $0,6-10 \mu \mathrm{m}$ & bis-GMA \\
\hline & Universal A & & - Ytterbium trifluoride & & bis-EMA \\
\hline & $\begin{array}{l}\text { Ivoclar-Vivadent, Schaan, } \\
\text { Liechtenstein }\end{array}$ & & - Mixed oxide and prepolymer, additives & & UDMA \\
\hline
\end{tabular}


then stored in distilled water at $37^{\circ} \mathrm{C}$. The control specimens were individually immersed in vials containing $5 \mathrm{~mL}$ of distilled water $(\mathrm{pH}$ 6.58) and incubated at $37^{\circ} \mathrm{C}$ for $24 \mathrm{~h}$. The vials were sealed to prevent evaporation of the solution. The solutions were renewed on a daily basis, and $\mathrm{pH}$ measurements were taken daily using a $\mathrm{pH}$ meter (HI 221; Hanna Instruments Inc. Woonsocket, RI, USA) before immersing each specimen. A third color measurement was taken after storage in colorant medium (T2).

\section{Tooth brushing}

The specimens were randomly divided into two groups (each containing 10 composite discs) for brushing with Crest 3D White Luxe Perfection or Crest 3D White Luxe Perfection Accelerator dentifrice (Procter \& Gamble GmbH, Schwalbach am Taunus, Germany). The composition and a description of each of these dentifrices are shown in Table 2. The brushing process included two 2-min brushing cycles daily, for a total of 60 cycles per month. Each brush cycle was standardized by use of a rechargeable electric toothbrush (comprising an Oral- $\mathrm{B}^{\circ}$ Vitality handle and an Oral- $\mathrm{B}^{\circledR}$ Precision Clean interchangeable brush head) with oscillating and rotating technology (7600 strokes per minute). The battery in the toothbrush was charged every 15 cycles in accordance with the manufacturer's instructions. The amount of dentifrice used was the minimum volume required to contact all the brush bristles. To avoid operator fatigue and overload during brushing, the toothbrush was fixed to a device to standardize the pressure (200 g) exerted by the brush bristles on the specimens. The brushing sequence was determined at random on a daily basis. After each brushing, the specimens were cleaned for $10 \mathrm{~min}$ in an ultrasonic tank to remove debris and remnants of the dentifrice to avoid interference with the results. At the end of the brushing cycles, the specimens were analyzed for the final color change (T3).

\section{Statistical analysis}

Two-way analysis of variance was used to evaluate the effects of type of material and staining agent on color change, including the possibility of interaction between these two factors, using SPSS for Windows version 22.0 software (IBM Corp., Armonk, NY, USA). The means were tabulated and compared using Tukey's honest significant difference test. The significance level was set at $5 \%$.

\section{Results}

The restorative material, staining agent, and the interaction between these two factors were found to have a statistically significant role in discoloration ( $\mathrm{p}=0.05$, analysis of variance). Tables 3 and 4 show the means and standard deviations of the color difference for each resin composite in each staining solution, along with the differences between groups. No significant color change was observed, with all groups being below the threshold for perceptibility of color change $(\Delta \mathrm{E}<0.8)$. Filtek Bulk Fill had higher $\Delta \mathrm{E}$ values for coffee staining and Tetric EvoVeram had higher $\Delta \mathrm{E}$ values for cola and red wine staining, but there was no statistically significant difference between the two composites ( $p>0.05)$. The 3D Perfection and 3D Whitening Accelerator groups both showed a decrease in $\Delta \mathrm{E}$ values in comparison with the values obtained after staining, but the difference was not statistically significant in either dentifrice group ( $>0.05)$. All groups showed clinically acceptable $\Delta \mathrm{E}$ values $(<3.3)$ after brushing.

Table 2. Composition of the whitening dentifrices used in the study

\begin{tabular}{|l|l|l|}
\hline Name & Manufacturer & Active ingredients \\
\hline $\begin{array}{l}\text { Crest 3D White Luxe } \\
\text { Perfection }\end{array}$ & Procter \& Gamble & $\begin{array}{l}\text { Glycerin, hydrated silica, sodium hexametaphosphate, aqua, aroma, silica, sodium lauryl sulphate, cocamidopropyl, betaine, } \\
\text { trisodium pyrophosphate, mica, chondrus crispus powder, sodium saccharin, peg-20m, sodium fluoride, xanthan gum, sodium } \\
\text { chloride, sucralose, limonene, sodium benzoate }\end{array}$ \\
\hline $\begin{array}{l}\text { Crest 3D White Luxe } \\
\text { Perfection Accelerator }\end{array}$ & Procter \& Gamble & $\begin{array}{l}\text { Glycerin, hydrated silica, sodium hexametaphosphate, propylene glycol, aqua, sodium lauryl sulfate, aroma, silica, poloxamer, } \\
\text { sodium saccharin, xanthan gum, cellulose gum, limonene }\end{array}$ \\
\hline
\end{tabular}

Table 3. Crest 3D White Luxe Perfection

\begin{tabular}{|c|c|c|c|c|c|}
\hline & & Mean (SD) at T1 & Mean (SD) at T2 & Mean (SD) at T3 & p-value \\
\hline \multirow{4}{*}{ FBF } & Water & $1,06(0.37)^{\mathrm{a}, 1}$ & $2.49(0.83)^{a, 1}$ & $2.76(1.59)^{\mathrm{a}, 1}$ & $>0.05$ \\
\hline & Cola & $1.40(0.50)^{\mathrm{a}, 1}$ & $4.00(1.45)^{\mathrm{b}, 2}$ & $3.16(2.18)^{\mathrm{b}, 1}$ & $<0.05$ \\
\hline & Coffee & $0,90(0.39)^{a, 1}$ & $6.42(0.61)^{b, 2}$ & $2.78(1.10)^{\mathrm{a}, 1}$ & $<0.05$ \\
\hline & Red wine & $0.73(0.53)^{\mathrm{a}, 1}$ & $4.47(1.25)^{\mathrm{b}, 2}$ & $3.73(1.89)^{\mathrm{b}, 1}$ & $<0.05$ \\
\hline \multirow{4}{*}{ TEC } & Water & $2.01(1.11)^{\mathrm{a}, 1}$ & $3.34(1.31)^{\mathrm{a}, 1}$ & $1.89(1.33)^{\mathrm{a}, 1}$ & $>0.05$ \\
\hline & Cola & $1.15(0.39)^{\mathrm{a}, 1}$ & $9.24(1.39)^{b, 2}$ & $2.29(0.81)^{\mathrm{a}, 1}$ & $<0.05$ \\
\hline & Coffee & $1.84(1.22)^{\mathrm{a}, 1}$ & $7.77(3.11)^{\mathrm{b}, 2}$ & $4.84(3.43)^{\mathrm{b}, 1}$ & $<0.05$ \\
\hline & Red wine & $1.53(0.97)^{\mathrm{a}, 1}$ & $7.13(3.90)^{b, 2}$ & $5.27(2.25)^{\mathrm{b}, 1}$ & $<0.05$ \\
\hline
\end{tabular}

T1, first reading after thermocycling; T2, second reading after immersion in different beverages; T3, third reading after brushing with whitening dentifrice. Means followed by different letters in the same line, and numbers in the same column, are significantly different $(\mathrm{p}<0.05)$. For control samples, no significant alteration was detected, irrespective of the composite tested

Table 4. Crest 3D White Luxe Perfection Accelerator.

\begin{tabular}{|c|c|c|c|c|c|}
\hline & & Mean (SD) at T1 & Mean (SD) at T2 & Mean (SD) at T3 & p-value \\
\hline \multirow[t]{4}{*}{ FBF } & Water & $0.94(0.35) \mathrm{a}, 1$ & $2.95(0.97) \mathrm{a}, 1$ & $3.84(2.06) \mathrm{a}, 1$ & $>0.05$ \\
\hline & Cola & $1.06(0.76) \mathrm{a}, 1$ & $5.13(1.47) b, 2$ & $3.93(1.14) b, 1$ & $<0.05$ \\
\hline & Coffee & $0.78(0.51)$ a, 1 & $6.49(1.98) b, 2$ & $2.70(1.78) \mathrm{a}, 1$ & $<0.05$ \\
\hline & Red wine & $1.19(0.42)$ a, 1 & $4.92(1.49) b, 2$ & $2.98(1.30) \mathrm{a}, 1$ & $<0.05$ \\
\hline \multirow[t]{4}{*}{ TEC } & Water & $1.28(0.36) \mathrm{a}, 1$ & $3.36(1.92) \mathrm{a}, 1$ & $2.57(0.93) \mathrm{a}, 1$ & $>0.05$ \\
\hline & Cola & $0.94(0.30) \mathrm{a}, 1$ & $7.80(1.96) b, 2$ & $4.78(1.32) b, 1$ & $<0.05$ \\
\hline & Coffee & $1.05(0.30) \mathrm{a}, 1$ & $6.75(0.74) b, 2$ & $3.64(2.08) \mathrm{a}, 1$ & $<0.05$ \\
\hline & Red wine & $1.81(1.27) \mathrm{a}, 1$ & $8.53(1.18) b, 2$ & $4.74(1.61) b, 1$ & $<0.05$ \\
\hline
\end{tabular}

Adding after immersion in different beverages; T3, third reading after brushing with whitening dentifrices. Means followed by different letters in the same line, and numbers in the same column, are significantly different $(\mathrm{p}<0.05)$. For control samples, no significant alteration was detected, irrespective of the composite tested. 


\section{Discussion}

The susceptibility of esthetic restorative materials to staining is influenced by various factors. In this study, the susceptibility of the composite resins to extrinsic staining after immersion in foodsimulating media may be related to the water sorption and solubility of the resin matrix [5]. The following three types of discoloration are the most commonly reported: external discoloration arising from accumulation of plaque and surface stains (extrinsic discoloration), color variations caused by superficial degradation or slight penetration of the surface or subsurface and the reaction of colorants within the superficial layer of resins (absorption), and discoloration caused by physicochemical reactions in the deepest layer of the material (intrinsic discoloration). Water is the carrier via which pigments penetrate into the resin matrix, and Dietschi et al. showed that susceptibility to staining tends to correspond with the water sorption rate [16].

The glass filler particles in composite resins do not absorb water. Therefore, a greater amount of resin matrix results in more sorption of water. It has been reported that composite resins containing smaller amounts of inorganic fillers are more susceptible to color change because the greater resin matrix volume allows greater water sorption [17]. These observations are supported by the finding in the present study that Tetric EvoCeram had higher discoloration values than $3 \mathrm{M}$ Filtek Bulk Fill. This higher staining susceptibility is explained by the lower filler content $(52 \% \mathrm{w} / \mathrm{w})$ of the Tetric EvoCeram bulk-fill composite.

The differences in $\Delta \mathrm{E}$ values could be related to differences in the type of filler particles used as well as in the resin matrix. Urethane dimethacrylate is more susceptible to being dissolved by foodsimulating solvents [18]. The composites tested in our study had the same monomer, but differed in their monomer ratios. The bis-GMA present in Tetric EvoCeram may have favored water sorption and increased the solubility of the polymers. Food-simulating substances penetrate the polymer matrix, damaging its structure and the areas of interface with filler particles, resulting in greater color alteration, as observed by Yesilyurt et al. [18] and Roselino et al. [19] Our present findings correspond with those of studies of methacrylate composites demonstrating an association between lower filler content and greater discoloration $[20,21]$.

The staining solutions used in this study were coffee, red wine, and cola, which are often consumed on a daily basis and are known to stain restorative materials $[17,22]$. Resin composites stored in distilled water were used as controls, and the color changes in this group were clinically acceptable $(\Delta \mathrm{E}<3.3)$, confirming that water absorption in itself does not alter the color of composites to any considerable extent.

To avoid bias being introduced by individual subjective evaluation of color, we used a spectrophotometer that allowed a quantitative assessment of color. The CIE $\mathrm{L}^{\star} \mathrm{a}^{\star} \mathrm{b}^{\star}$ system was used to measure the color of the samples because it can detect small color differences and has been widely used in previous studies [16,23]. It is accepted that a color difference of $\Delta \mathrm{E}<1.0$ is imperceptible to the human eye but that a $\Delta \mathrm{E}$ value $>3.3$ is esthetically unacceptable [12].

In the present study, the two composites were stained to a similar magnitude when aged in the various types of medium. However, no significant differences in staining were observed compared to the control group aged in water. Thus, all three null hypotheses tested herein were accepted. In accordance with our findings, the literature indicates that degradation of resin composite restorations is influenced by factors related to the materials used and by various abrasive/erosive challenges related to oral hygiene and dietary composition. When in contact with staining agents, resin composites undergo sorption of extrinsic pigments, which is increased when these materials are exposed to alcoholic media (beverages and/or mouth rinses) or acidic media (beverages and biofilm) because of further degradation of the organic matrix [24-27].

Immersion in coffee, cola, and red wine caused significant color variations. The adsorption and/or absorption of colorants may explain the discoloration produced by coffee. The absorption and penetration of colorants into the organic phase of materials were probably attributable to the compatibility of the polymer phase with the yellow colorants contained in coffee [28]. In our study, coffee caused greater color changes than red wine in all the materials tested. This is in accordance with other studies demonstrating that certain substances (e.g., coffee) cause more severe staining than others [29,30]. According to Um and Ruyter [28], although cola has the lowest $\mathrm{pH}$ and therefore has the potential to damage the surface integrity of resin composite materials, it did not produce as much discoloration as coffee and wine in their study, possibly because of its lack of yellow colorant.

It has been previously reported that alcohol tends to degrade the surface properties of resin composites [31-33] and that rougher and more degraded composite surfaces provide a greater surface area for adsorption of pigments, thereby leading to more staining [32,33]. Therefore, it is possible that the alcohol component in wine caused more discoloration by roughening the surface of the composite.

Although both resin composites tested in the present study underwent significant discoloration according to the duration of exposure to coffee, cola, or red wine, brushing was able to reduce the intensity of the color change. Tooth brushing is reportedly associated with reduced retention of extrinsic pigments [34,35].

There are several ways to remove superficial stains from resin composites, i.e., tooth brushing, repolishing, and bleaching. Of these, tooth brushing is highly dependent on the type of dentifrice used, so there may be some variation in its ability to remove discoloration. In our study, we tested two different types of whitening dentifrice for their ability to remove stains, used an electric toothbrush to standardize patients' brushing habits, and evaluated the color change in the resin composites using a colorimetric method [34].

We found that tooth brushing was unable to remove the color change in either resin composite completely, suggesting that both intrinsic and extrinsic staining had occurred, in that the susceptibility of a resin to staining is modulated by the degree of conversion and physicochemical characteristics, particularly the water sorption rate [36].

We also observed significant changes in color when a brushing protocol was used in our study. The effect of brushing on the surface of a composite varies according to its composition, i.e., particle size, type of resin matrix, and degree of conversion after polymerization [37]. Whitening dentifrices also vary in terms of whether the active ingredient is hydrogen peroxide, pyrophosphates, or blue covarine. Phosphate materials, such as pyrophosphate, tripolyphosphate, and hexametaphosphate, tend to have a strong binding affinity for enamel, dentine, and tartar, and during adsorption these materials have been shown to desorb stain components [38,39]. In the present study, we evaluated two types of sodium hexametaphosphate-containing dentifrices for their ability to remove discolored composite resin.

Sodium hexametaphosphate is a longer-chain variant of pyrophosphate and contains $10-12$ repeating pyrophosphate subunits. This compound has multiple binding sites, which could 
increase its retention at tooth surfaces to a greater degree than that possible with pyrophosphate and therefore may reduce adsorption of staining chromogens at the tooth surface [40]. However, we found no statistically significant difference in the ability of two commonly used whitening dentifrices to reduce discoloration of the composite resins used in this study.

Our study has some limitations, mainly the short brushing time and brushing without artificial saliva. However, longer brushing times tend to increase the surface roughness of composites when a dentifrice is used. Moreover, use of artificial saliva could have decreased the ability of the different types of medium to stain the composites, and our intention was to mimic the worst-case scenario for staining. Further studies are needed to establish a correlation between depth of penetration of staining agents and the ability to remove the resulting discoloration, as well as to assess whether duration of exposure to staining agents has a direct influence on the pigmentation of composite resins.

\section{Conclusions}

The two bulk-fill composites used in this study developed esthetically significant discoloration when immersed in coffee, cola, and red wine. Although brushing with whitening dentifrices reduced the discoloration of the composite resins, the discoloration was not fully removed. Most of the staining observed on resin composites is superficial and can be removed mostly by brushing procedures. Therefore, limiting the exposure of restorations to potentially staining substances in the diet and in oral hygiene products is important for maintaining the esthetic appearance of the restoration.

\section{References}

1. Lazarchik DA, Hammond BD, Sikes CL, Looney SW, Rueggeberg FA (2007) Hardness comparison of bulk-filled/transtooth and incremental-filled/occlusally irradiated composite resins. J Prosthet Dent 98: 129-140. [Crossref]

2. Yoshikawa T, Morigami M, Sadr A, Tagami J (2013) Acceleration of curing of resin composite at the bottom surface using slow-start curing methods. Dent Mater J 32: 999-1004. [Crossref]

3. Furness A, Tadros MY, Looney SW, Rueggeberg FA (2014) Effect of bulk/incremental fill on internal gap formation of bulk-fill composites. J Dent 42: 439-449. [Crossref]

4. Poggio C, Ceci M, Beltrami R, Mirando M, Wassim J, et al. (2016) Color stability of esthetic restorative materials: a spectrophotometric analysis. Acta Biomater Odontol Scand 2: 95-101. [Crossref]

5. Borges A, Caneppele T, Luz M, Pucci C, Torres C (2014) Color stability of resin used for caries infiltration after exposure to different staining solutions. Oper Dent 39: 433440. [Crossref]

6. Joiner A (2004) Tooth colour: a review of the literature. J Dent 32 Suppl 1: 3-12. [Crossref]

7. Villalta P, Lu H, Okte Z, Garcia-Godoy F, Powers JM (2006) Effects of staining and bleaching on color change of dental composite resins. J Prosthet Dent 95: 137-142. [Crossref]

8. Sarac D, Sarac YS, Kulunk S, Ural C, Kulunk T (2006) The effect of polishing techniques on the surface roughness and color change of composite resins. J Prosthet Dent 96: 33-40. [Crossref]

9. Ergücü Z, Türkün LS, Aladag A (2008) Color stability of nanocomposites polished with one-step systems. Oper Dent 33: 413-420. [Crossref]

10. Türkün LS, Türkün M (2004) Effect of bleaching and repolishing procedures on coffee and tea stain removal from three anterior composite veneering materials. $J$ Esthet Restor Dent 16: 290-301. [Crossref]

11. Guler AU, Yilmaz F, Kulunk T, Guler E, Kurt S (2005) Effects of different drinks on stainability of resin composite provisional restorative materials. J Prosthet Dent 94 : 118-124. [Crossref]

12. Bagheri R, Burrow MF, Tyas M (2005) Influence of food-simulating solutions and surface finish on susceptibility to staining of aesthetic restorative materials. $J$ Dent 33 : 389-398. [Crossref]
13. Valkenburg C, Slot DE, Bakker EW, Van der Weijden FA (2016) Does dentifrice use help to remove plaque? A systematic review. J Clin Periodontol 43: 1050-1058. [Crossref]

14. Monteiro B, Spohr AM (2015) Surface Roughness of Composite Resins after Simulated Toothbrushing with Different Dentifrices. J Int Oral Health 7: 1-5. [Crossref]

15. Soeteman GD, Valkenburg C, Van der Weijden GA, Van Loveren C, Bakker E, et al. (2017) Whitening dentifrice and tooth surface discoloration - a systematic review and meta-analysis International Journal of Dental Hygiene 2.

16. Dietschi D, Campanile G, Holz J, Meyer JM (1994) Comparison of the color stability of ten new generation composites: An in vitro study. Dent Mater 10: 353-362. [Crossref]

17. Fontes ST, Fernández MR, de Moura CM, Meireles SS (2009) Color stability of a nanofill composite: effect of different immersion media. J Appl Oral Sci 17: 388-391. [Crossref]

18. Yesilyurt C, Yoldas O, Altintas SH, Kusgoz A (2009) Effects of food-simulating liquids on the mechanical properties of a silorane-based dental composite. Dent Mater J 28 362-367. [Crossref]

19. Roselino Lde M, Cruvinel DR, Chinelatti MA, Pires-de-Souza Fde C (2013) Effect of brushing and accelerated ageing on color stability and surface roughness of composites. J Dent 54-61. [Crossref]

20. Manojlovic D, Dramicanin MD, Lezaja M, Pongprueksa P, Van Meerbeek B, et al (2016) Effect of resin and photoinitiator on color, translucency and color stability of conventional and low-shrinkage model composites. Dent Mater 32: 183-191. [Crossref]

21. Samra AP, Pereira SK, Delgado LC, Borges CP (2008) Color stability evaluation of aesthetic restorative materials. Braz Oral Res 22(3): 205-10. [Crossref]

22. Arocha MA, Mayoral JR, Lefever D, Mercade M, Basilio J, et al. (2014) Color stability of siloranes versus methacrylate-based composites after immersion in staining solutions. Clin Oral Investig 17: 1481-1487. [Crossref]

23. Ren YF, Feng L, Serban D, Malmstrom HS (2012) Effects of common beverage colorants on color stability of dental composite resins: the utility of a thermocycling stain challenge model in vitro. J Dent 48-56. [Crossref]

24. da Silva EM, Dória J, da Silva Jde J, Santos GV, Guimarães JG, et al. (2013) Longitudinal evaluation of simulated toothbrushing on the roughness and optical stability of microfilled, microhybrid and nanofilled resin-based composites. $J$ Dent 41 1081-1090. [Crossref]

25. Ferracane JL (2006) Hygroscopic and hydrolytic effects in dental polymer networks Dent Mater 22: 211-222. [Crossref]

26. Kaizer Mda R, Diesel PG, Mallmann A, Jacques LB (2012) Ageing of silorane-based and methacrylate-based composite resins: effects on translucency. $J$ Dent 64-71. [Crossref]

27. da Silva EM, de Sá Rodrigues CU, Dias DA, da Silva S, Amaral CM, et al. (2014) Effect of toothbrushing-mouthrinse-cycling on surface roughness and topography of nanofilled, microfilled, and microhybrid resin composites. Oper Dent 39: 521-529. [Crossref]

28. Um CM, Ruyter IE (1991) Staining of resin-based veneering materials with coffee and tea. Quintessence Int 22: 377-386. [Crossref]

29. Mundim FM, Garcia Lda F, Pires-de-Souza Fde C (2010) Effect of staining solutions and repolishing on color stability of direct composites. J Appl Oral Sci 18: 249-254. [Crossref]

30. Barutcigil Ç, Yildiz M (2012) Intrinsic and extrinsic discoloration of dimethacrylate and silorane based composites. J Dent 57-63. [Crossref]

31. Sarrett DC, Coletti DP, Peluso AR (2000) The effects of alcoholic beverages on composite wear. Dent Mater 16: 62-67. [Crossref]

32. Igarasi S, Akaoka H, Komatsu H, Shimokobe H, Okada Y (1976) Influence of surface roughness of staining tendency in composite resin filling Japan. Journal of Conservative Dentistry 19: 116-22.

33. Reis AF, Giannini M, Lovadino JR, Ambrosano GM (2003) Effects of various finishing systems on the surface roughness and staining susceptibility of packable composite resins. Dent Mater 19: 12-8. [Crossref]

34. Lepri CP, Palma-Dibb RG (2012) Surface roughness and color change of a composite: influence of beverages and brushing. Dent Mater J 31: 689-696. [Crossref]

35. Omata Y, Uno S, Nakaoki Y, Tanaka T, Sano H, et al. (2006) Staining of hybrid composites with coffee, oolong tea, or red wine. Dent Mater J 25: 125-131. [Crossref] 
36. Manabe A, Kato Y, Finger WJ, Kanehira M, Komatsu M (2009) Discoloration of coating resins exposed to staining solutions in vitro. Dent Mater J 28: 338-343. [Crossref]

37. Heintze SD, Forjanic M, Ohmiti K, Rousson V (2010) Surface deterioration of dental materials after simulated toothbrushing in relation to brushing time and load. Dent Mater 26: 306-319. [Crossref]

38. White DJ (2002) A new and improved "dual action" whitening dentifrice technologysodium hexametaphosphate. J Clin Dent 13: 1-5. [Crossref]
39. Shellis RP, Addy M, Rees GD (2005) In vitro studies on the effect of sodium tripolyphosphate on the interactions of stain and salivary protein with hydroxyapatite. $J$ Dent 33: 313-324. [Crossref]

40. Baig A, He T, Buisson J, Sagel L, Suszcynsky-Meister E, et al. (2005) Extrinsic whitening effects of sodium hexametaphosphate - a review including a dentifrice with stabilized stannous fluoride. Compend Contin Educ Dent 47-53. [Crossref]

Copyright: (C2018 Kamheya M. This is an open-access article distributed under the terms of the Creative Commons Attribution License, which permits unrestricted use, distribution, and reproduction in any medium, provided the original author and source are credited. 